International Journal of Pure and Applied Mathematics

Volume 110 No. 1 2016, 183-192

ISSN: 1311-8080 (printed version); ISSN: 1314-3395 (on-line version)

url: http://www.ijpam.eu

doi: 10.12732/ijpam.v110i1.17

ijpam.eu

\title{
ASSESSMENT OF THE IMPACT OF RIVERBEDS DEPTH IN THE NORTHERN PART OF THE VOLGA-AKHTUBA FLOODPLAIN ON THE DYNAMICS OF ITS FLOODING
}

\author{
Anna Vasilchenko ${ }^{1}$, Alexander Voronin ${ }^{2}$, Andrey Svetlov ${ }^{3}$, Nare Antonyan ${ }^{4}$ \\ 1,2,3,4 Mathematics and IT Department \\ Volgograd State University \\ pr. Universitetsky, 100, Volgograd, 400062, RUSSIA
}

\begin{abstract}
On the basis of numerical hydrodynamic and geoinformation modeling we evaluate the influence of small riverbeds depth in the northern part of the Volga-Akhtuba floodplain on the dynamics of its flooding. It was found that the riverbeds depth integrally has a little impact on the value of total land area of flood inundation. Also we show that the local impact of this characteristic on some parts of the territory is large enough. Based on the simulation results we assess the effectiveness of area irrigation project by deepening the riverbeds.
\end{abstract}

AMS Subject Classification: 86-08, 86A05, 93A30, 93E10

Key Words: Volga-Akhtuba floodplain, riverbeds depth, hydrological modeling, hydrodynamic model

\section{Introduction}

The Volga - Akhtuba floodplain (VAF) is located in the lower reaches of the Volga river, its length is about $450 \mathrm{~km}$, the area of its territory is more than 20 thousand sq. $\mathrm{km}$. On its territory there are a large number of riverbeds through which spring flooding takes place. The VAF includes the natural

\footnotetext{
Received: July 29, 2016

Revised: $\quad$ August 28, 2016

Published: October 21, 2016

(c) 2016 Academic Publications, Ltd.

url: www.acadpubl.eu

$\S_{\text {Correspondence author }}$
} 
park with valuable species of flora and fauna, a large number of settlements, and it's a place to do agricultural, forestry and recreation business. In the immediate vicinity of the northern part of the VAF there are large cities of Volgograd and Volzhsky, and the VAF ecosystem is important for their public health. Life of the VAF ecosystem is completely determined by spring floods of the Volga river, which is regulated by the Volga Hydroelectric Station (VHS) since 1959 .

This mode is significantly different from the natural one. In particular, significantly reduced the maximum and average values of the flood volume [6]. As the result of reducing the flood volume we have the shoaling the numerous riverbeds of the VAF due to reduction of the flooding self-cleaning. This effect is much stronger in the northern part of the VAF due to human activities: shores plowing, devastation of riverine forests, construction of dams. Degradation of the VAF riverbeds contributes to a further reduction of flooding its territory.

Slowing the process of dewatering the northern part of the VAF is an urgent problem. It is widely thought that the riverbeds deepening on its territory is a possible way to solve the problem. The only way for preliminary analysis of the project effectiveness is the hydrodynamic and GIS modeling. The great length of the riverbeds (more than $800 \mathrm{~km}$ in the northern part of the VAF) requires a preliminary analysis of the alternative ways of the spatial distribution of project activities in order to maximize their effectiveness. The solutions of some particular problems in the field of this problem are presented in the papers $[7,8]$. This paper presents the results of modeling the effects of the riverbeds depth changes as imitation of their degradation and recovery for the entire territory of the northern part of the VAF.

\section{GIS Modeling of the VAF Relief}

The basis of the digital terrain model (DTM) of the VAF are satellite data of ASTER [3] and SRTM [4] with resolution up to 20 meters into the Earth plane, and up to $0.5 \mathrm{~m}$ vertically. With the Landsat [5] we can obtain relevant high resolution data (15-30 meters per pixel). Also we used open topographic maps at 1:50,000 scale to add attributive data to objects. Digital map of floodplain riverbeds and river bottoms is created by vectorization of topographic and pilot riverbeds maps of the VAF, the Volga and the Akhtuba [1] with field survey results [2]. The DTM has annual update by satellite images from US Geological Survey site [5] (Landsat 8 satellite), as well as by GPS-measurements of flood inundation boundaries. Vector map of the northern part of the VAF in 2016 
includes the hydraulic system layer with 1542 riverbeds objects with a total length of $887 \mathrm{~km}$, the infrastructure layer with 118 settlements, and the terrain layer with more than 15 thousand relief features. To solve the control problem we consider the hydrological structure of the northern part territory of the VAF with two hierarchical levels of its riverbeds. The highest level of the structure consists of three main watercourse (the Volga river, the Akhtuba river and the Pakhotny yerik). The second level consists of the associated respectively 14, 15 and 29 riverbeds, which are almost evenly distributed over the main watercourse riverbeds (local systems). Local systems basins form the natural hydrological zones (fig. 1), and we use them as the basis of this study.

\section{Hydrodynamic Modeling of Floods}

In this paper we use the computational model of the surface water dynamics $[9,10,11,12,13]$. This model takes into account all the main factors of flooding areas: surface and underground sources of water - dams, precipitations, springs, groundwater outflow to the land surface; terrain relief with human development areas and water bottom topography; properties of the underlying surface - the bottom friction, infiltration (new multi-layer non-linear model); internal viscous friction; wind effects — wave surges; Earth's rotation - the Coriolis force; evaporation.

The model adequacy is confirmed by comparison with the water level observations at four gauging stations in the northern part of the VAF and the area of the water surface in different years by the Landsat- 8 satellite data. The parallel OpenMP, CUDA, OpenMP-CUDA versions of the computational module of CSPH-TVD method reduced the computational complexity of the problem to 700 times. The results of hydrodynamic modeling of flood events in the territory of the northern part of the $\operatorname{VAF}$ are presented in $[9,10,11,12,13]$.

Analysis of satellite images and the results of hydrodynamic calculations showed that the flooded territory area is determined by the constant flow $Q$ and the duration of the flood first phase $t$. If $Q \leq 17,000 \mathrm{~m}^{3} / \mathrm{s}$ then the territory is not flooded, and if $Q \geq 30,000 \mathrm{~m}^{3} / \mathrm{s}$ and $t \geq 5$ days then there is a catastrophic flooding. The first phase of the controlled flood lasts no more than 10 days, so in this paper we used this value.

Table 1 shows the values of the flood inundation area $S$ in the northern part of the VAF for different values of flood hydrograph $Q$ and $t=10$ days. Map of flood inundation territories in the northern part of the VAF with $Q=$ $25,000 \mathrm{~m}^{3} / \mathrm{s}$ and $t=10$ days is shown in Figure 2 . 


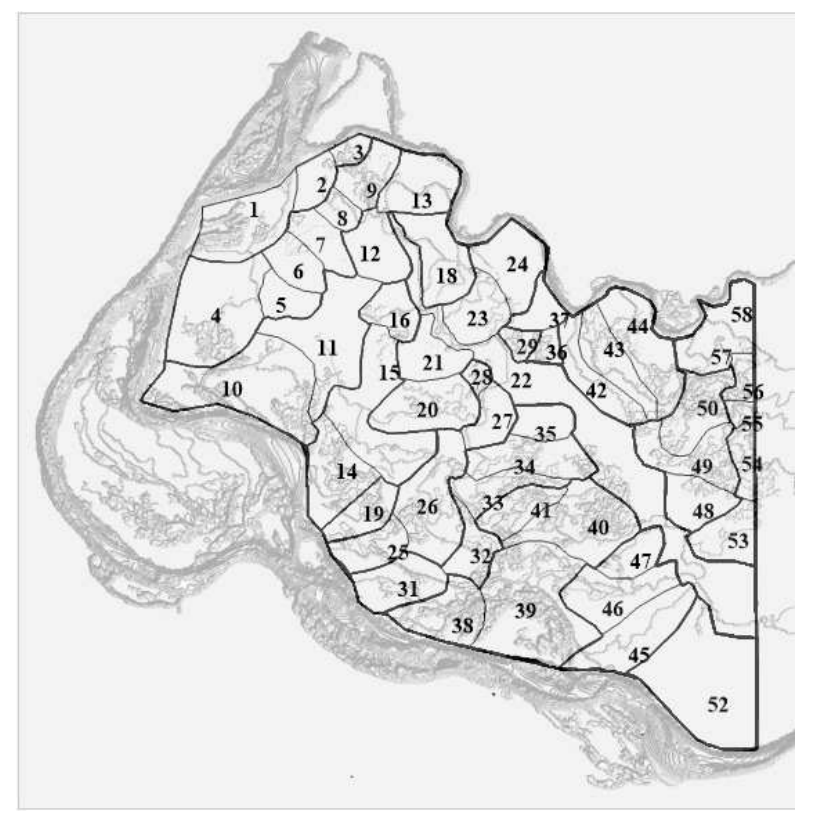

Figure 1: Map of the riverbeds areas in the northern part of the VAF

Table 1: The flood inundation area $S\left(\mathrm{~km}^{2}\right)$ in the northern part of the VAF with different values of flood hydrograph $Q$ (thous. $\mathrm{m}^{3} / \mathrm{s}$ ) and $t=10$ days

\begin{tabular}{|c|c|c|c|c|c|c|c|c|c|}
\hline $\mathrm{Q}$ & 17 & 18 & 19 & 20 & 21 & 22 & 23 & 24 & 25 \\
\hline $\mathrm{S}$ & 218 & 260 & 327 & 418 & 629 & 872 & 1181 & 1455 & 2005 \\
\hline
\end{tabular}

\section{Modeling the Effect of Changes in the Riverbeds Depth}

Computational experiments [7, 8] showed that the function of the flooded area $S$ is most sensitive to the riverbeds depth in the joints of the main watercourses and local riverbeds of the VAF. These places were centers of the project territories with a variable radius. Next we present the results of hydrodynamic modeling of flood dynamics in the VAF for series of virtual DTM with variable riverbeds depth within the project territory (the same in each hydrological 


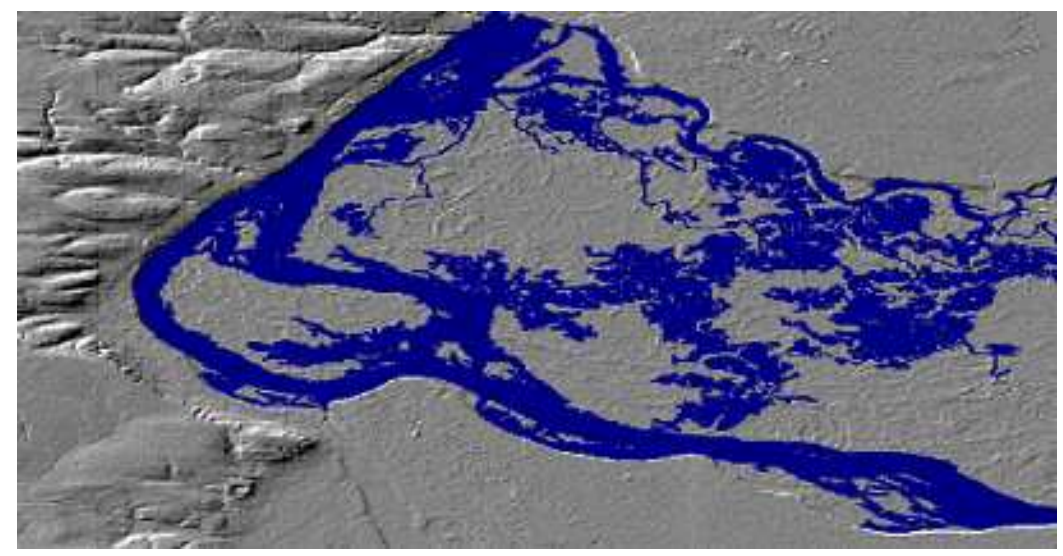

Figure 2: Water distribution over the territory of the VAF with $Q=$ $25,000 \mathrm{~m}^{3} / \mathrm{s}$ and $t=10$ days

zone) located within a distance $L=1-3 \mathrm{~km}$ from the joints of the main watercourses and local riverbeds of the VAF. We put initial riverbeds depth $h=2$ $\mathrm{m}$. We vary the difference $z$ in riverbeds depth from 0 to $2 \mathrm{~m}$, the value of $L$ from $1 \mathrm{tp} 3 \mathrm{~km}$, the value of the flood hydrograph of VHS $Q$ within 17-25 thousand $\mathrm{m}^{3} / \mathrm{s}$ (which corresponds to the statistics for the last 50 years). And we assume the duration of the flood first phase $t=10$ days.

According our results the maximum total growth of the flooded area is the highest $\left(11 \mathrm{~km}^{2}\right.$, or $15 \%$ ) at $Q=20,000 \mathrm{~m}^{3} / \mathrm{s}$ and $z=1 \mathrm{~m}$. If $Q=17$ and 22 thous. $\mathrm{m}^{3} / \mathrm{s}$ and $z=1 \mathrm{~m}$ then we have a small total growth of the flooded area (approximately $2.5 \%$ ) for $t=10$ days. The dynamics of growth of total flooded area $\Delta S$ have different directions at different $t$ (see for instance Fig. 3 ).

Zonal effects have different directions and distinguished. For instance, at $Q=22,000 \mathrm{~m}^{3} / \mathrm{s}$ on the 10 th day of the flood in 20 areas we have a significant positive effect (up to $10 \%$ ), and in 6 areas the effect was negative ( $8 \%$ ). In other areas the effect was close to zero (Fig. 4). If we put $Q=25,000 \mathrm{~m}^{3} / \mathrm{s}$ then multidirectional effect in all areas did not exceed $3 \%$.

For $z=2 \mathrm{~m}$ and for all $Q$ the maximum total and zonal growth of the flooded area were lower than at $z=1 \mathrm{~m}$.

To assess the possible development trends of the VAF dehydration with beds further degradation we have conducted a series of similar computational experiments with the riverbeds depth reduced by $1 \mathrm{~m}(z=-1 \mathrm{~m})$. If $Q=$ $17,000 \mathrm{~m}^{3} / \mathrm{s}$ then the largest decrease in the total area of flood inundation was $3.5 \mathrm{~km}^{2}$. If $Q=22,000 \mathrm{~m}^{3} / \mathrm{s}$ then this value was $9 \mathrm{~km}^{2}$. And it was zero effect 


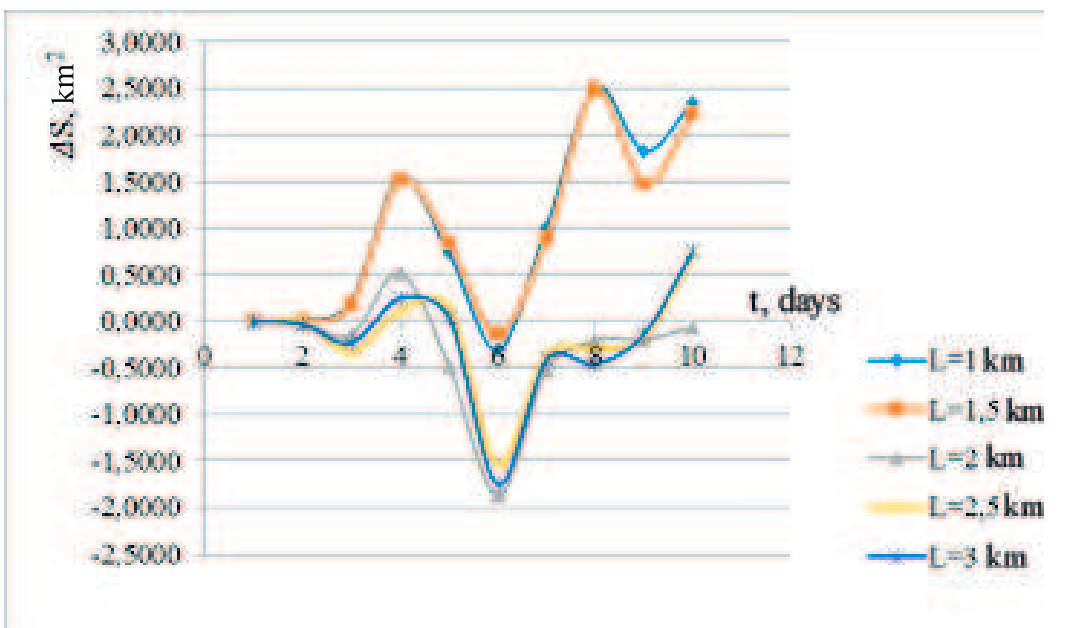

Figure 3: Dynamics of growth of total flooded area $\Delta S$ for $Q=$ $22,000 \mathrm{~m}^{3} / \mathrm{s}, z=1 \mathrm{~m}$

if $Q=25,000 \mathrm{~m}^{3} / \mathrm{s}$. Figure 5 shows the dynamics of reduction of the flooded area $\Delta S(t)$ at $Q=22,000 \mathrm{~m}^{3} / \mathrm{s}$. Figure 6 shows the zonal effects of riverbeds depth reduction.

\section{Optimization of the Project to Riverbeds Deepening}

Presented in Section 3 results show multidirectional changes in the area of flood inundation of different hydrological zones in the northern part of the VAF in case of the riverbeds deepening in the operating range of parameters $Q$ and $t$ of controlled flood. This fact testifies to the relevance of targeted selection of hydrological zones for the most effective implementation of the project to riverbeds deepening. To solve this problem we built the zones rating tables. It allows to put the zones in order by the size of increment of flood inundation area $\Delta S_{\mathrm{i}}(i=1, \ldots, 58)$ as a result of the riverbeds deepening to $1 \mathrm{~m}$ for different values of $Q$ and $L$. On the basis of these tables we plot a dependence of "costeffect" type, where the cost is the total value $\sum L_{\mathrm{i}}\left(L_{\mathrm{i}}=L, i=1, \ldots, 58\right)$. This value is proportional to the total length of the deepened riverbeds. The effect is the total flooded area growth $\Delta S_{\mathrm{i}}$. For example, the value $\sum L_{\mathrm{i}}=10$, $L=2 \mathrm{~km}$, corresponds to the selection of the first five zones of the rating table.

The calculations show that the maximum effectiveness of the project is 


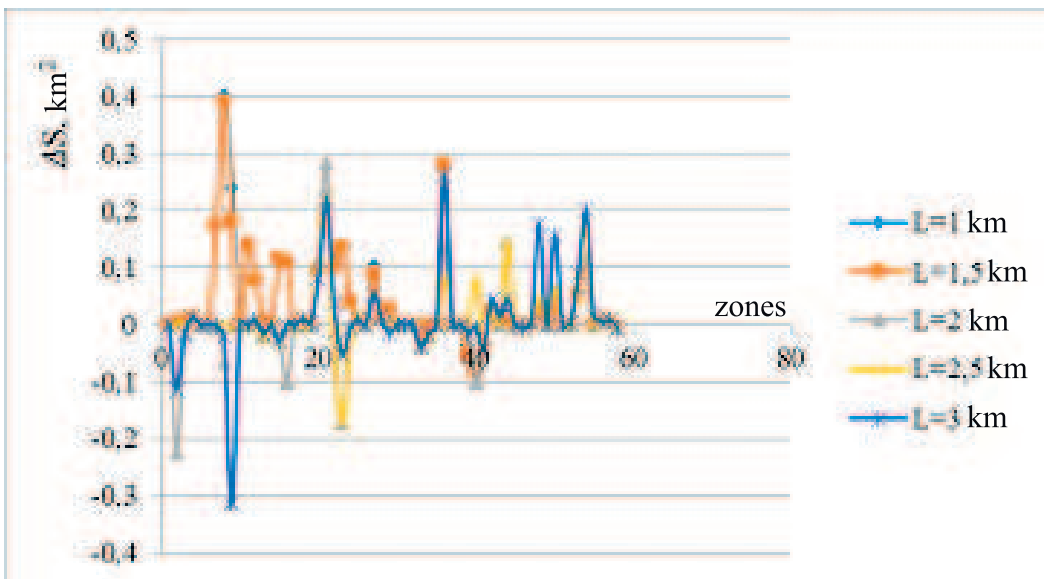

Figure 4: Growth of flooded area of hydrological zones $\Delta S$ at $Q=$ $22,000 \mathrm{~m}^{3} / \mathrm{s}, z=1 \mathrm{~m}, t=10$ days. The abscissa indicates a zone number

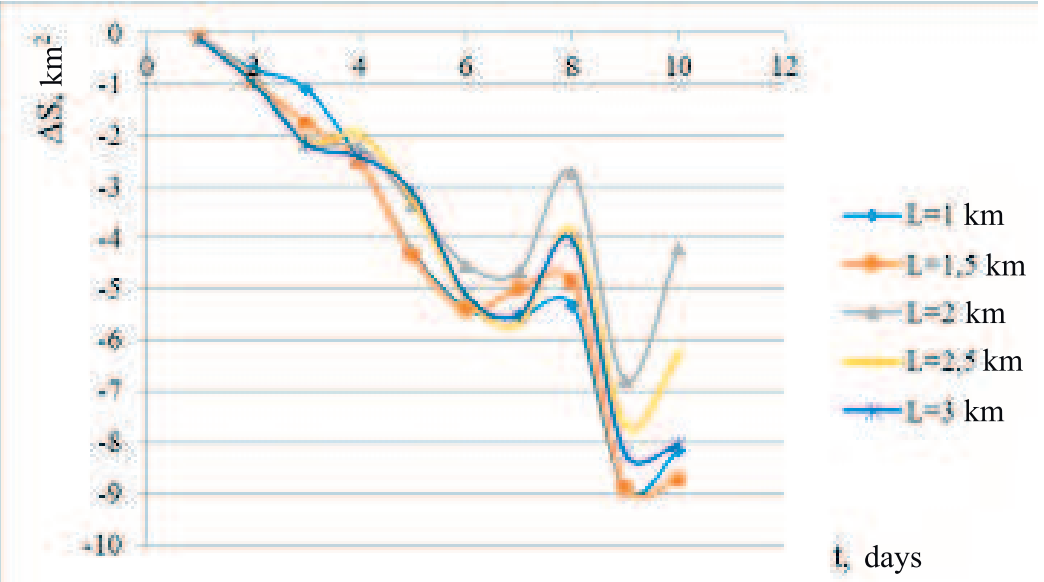

Figure 5: Dynamics of reduction of the flooded area at $Q=$ $22,000 \mathrm{~m}^{3} / \mathrm{s}, z=-1 \mathrm{~m}$

achieved with the most probable value $Q=22,000 \mathrm{~m}^{3} / \mathrm{s}$. Table 2 shows a fragment of the corresponding rating table for the hydrological zones. Figure 7 


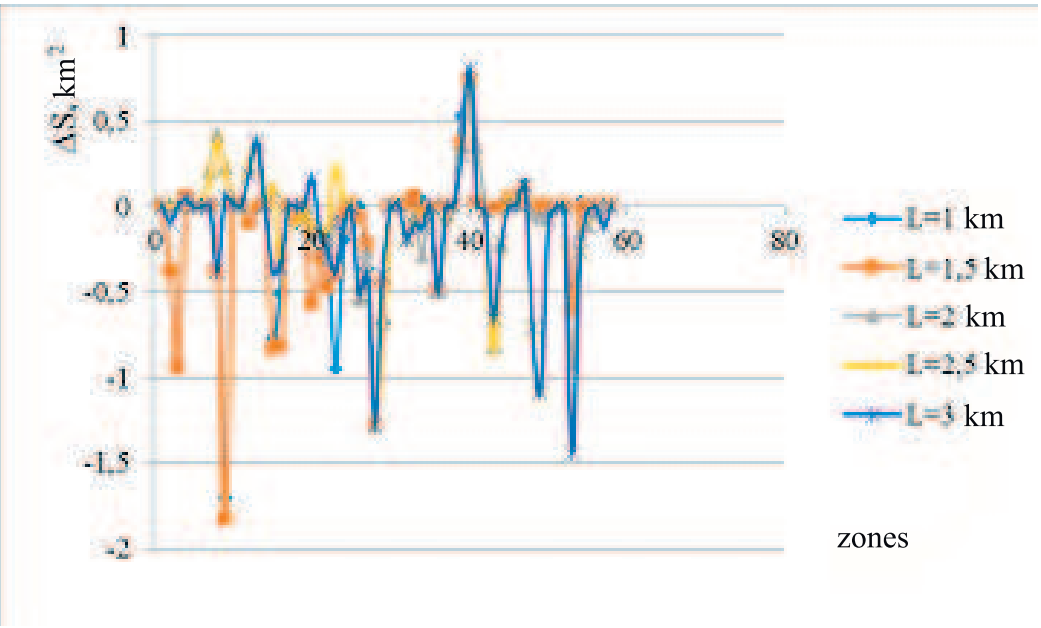

Figure 6: Changes in flooded area of hydrological zones $\Delta S$ at $Q=$ $22,000 \mathrm{~m}^{3} / \mathrm{s}, z=-1 \mathrm{~m}, t=10$ days. The abscissa indicates a zone number

shows the corresponding dependence of "cost-effect" type.

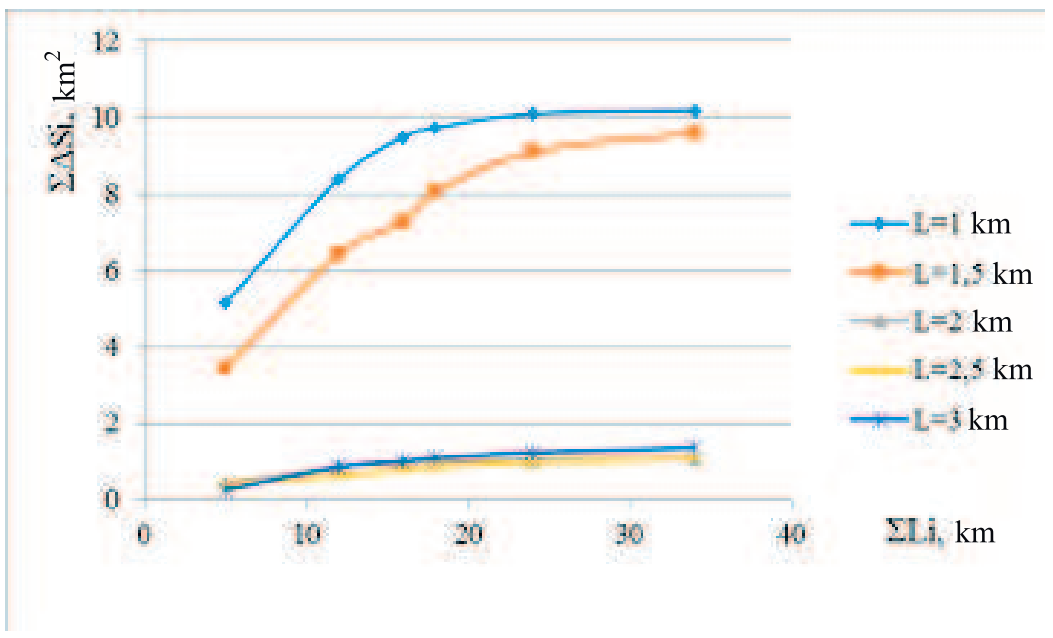

Figure 7: "Cost-effect" dependence at $Q=22000 \mathrm{~m}^{3} / \mathrm{s}$

As a conclusion we should note that the error in the calculation of the total 
Table 2: Fragment of zones rating by expected flooding growth efficiency $\left(\Delta S_{\mathrm{i}}\right)$ on the 10th day of flood at $Q=22,000 \mathrm{~m}^{3} / \mathrm{s}$ and $L=1 ; 1.5 ; 2 ; 2.5 ; 3 \mathrm{~km}$

\begin{tabular}{|c|c|c|c|c|c|c|c|c|c|c|}
\hline $\begin{array}{l}\text { Zone } \\
\text { rat- } \\
\text { ing }\end{array}$ & $\begin{array}{l}\text { Zone } \\
\text { num. }\end{array}$ & $\begin{array}{l}\Delta S_{\mathrm{i}} \\
\text { at } \\
L= \\
1 \mathrm{~km}\end{array}$ & $\begin{array}{l}\text { Zone } \\
\text { num. }\end{array}$ & $\begin{array}{l}\Delta S_{\mathrm{i}} \\
\text { at } \\
L \\
1.5 \\
\mathrm{~km}\end{array}$ & $\begin{array}{l}\text { Zone } \\
\text { num. }\end{array}$ & $\begin{array}{l}\Delta S_{\mathrm{i}} \\
\text { at } \\
L= \\
2 \mathrm{~km}\end{array}$ & $\begin{array}{l}\text { Zone } \\
\text { num. }\end{array}$ & $\begin{array}{l}\Delta S_{\mathrm{i}} \\
\text { at } \\
L \\
2.5 \\
\mathrm{~km}\end{array}=$ & $\begin{array}{l}\text { Zone } \\
\text { num. }\end{array}$ & $\begin{array}{l}\Delta S_{\mathrm{i}} \\
\text { at } \\
L=3 \\
\mathrm{~km}\end{array}$ \\
\hline 1 & 8 & 0.4025 & 8 & 0.3925 & 21 & 0.285 & 21 & 0.2225 & 36 & 0.2625 \\
\hline 2 & 36 & 0.2775 & 36 & 0.2825 & 44 & 0.145 & 54 & 0.1775 & 21 & 0.22 \\
\hline 3 & 9 & 0.24 & 21 & 0.185 & 36 & 0.135 & 44 & 0.145 & 54 & 0.2 \\
\hline 4 & 21 & 0.19 & 9 & 0.1825 & 54 & 0.115 & 20 & 0.1 & 48 & 0.1775 \\
\hline 5 & 7 & 0.175 & 7 & 0.175 & 20 & 0.11 & 36 & 0.0825 & 50 & 0.1575 \\
\hline \multicolumn{11}{|l|}{$\ldots$} \\
\hline 30 & 43 & 0.0025 & 43 & 0.0025 & 30 & 0 & 17 & 0 & 17 & 0 \\
\hline
\end{tabular}

area of flood inundation based on the error of the used DTM is not exceed $5 \%$ [9]. An error estimate for the calculation of changes $\Delta S_{\mathrm{i}}$ in different zones is an independent complex problem. Therefore the results this work can serve as a basis for further research in two directions: as a justification for the decisionmaking within the "zone" strategy, as well as the research on comparative assessment of the effectiveness of this strategy among the other strategies of flooding the territory of northern part of the VAF.

\section{Acknowledgements}

The reported study was partially supported by RFBR, research project No. 16-48-340147.

\section{References}

[1] Atlas of the unified deep-water system of the European part of Russia. V. 7: The Volga River. From Volgograd hydroelectric station to Astrakhan. S.Peterburg: Volgo-Balt, 2009. (in Russian)

[2] Barmin A.N., Golub V.B., Iolin M.M. Indication of environmental changes in the northern part of Volga-Akhtuba bottomland with the use of ecological scales by L.G. Ramensky and DCA-ordination // Izvestia vuzov "Geodesy and aerophotography", 5, 2010, 21-24. (in Russian) 
[3] Suwandana E., Kawamura K., Sakuno Y. etc. Thematic information content assessment of the ASTER GDEM: A case study of watershed delineation in West Java, Indonesia, Remote Sensing Letters, 3 (5), 2012, 423-432, DOI:10.1080/01431161.2011.593580.

[4] Rabus B., Eineder M., Roth A., etc. The shuttle radar topography mission - a new class of digital elevation models acquired by spaceborne radar, ISPRS Journal of Photogrammetry and Remote Sensing, 57 (4), 2003, 241-262, DOI:10.1016/S0924-2716(02)00124-7.

[5] Roy D.P., Wulder M.A., Loveland T.R., Woodcook C.E., Allen R.G., Anderson M.C., Helder D., Irons J.R., Johnson D.M., Kennedy R. et al. Landsat-8: Science and product vision for terrestrial global change research, Remote Sens. Environ., 145, 2014, 154-172, DOI:10.1016/j.rse.2014.02.001.

[6] Zemlyanov I.V., Gorelits O.V., Pavlovskiy A.E. Analysis of the environmental effects of operating the Volgograd reservoir for biodiversity major water-marsh areas in the Lower Volga, Research project report, Moscow, SIO, 2010. (in Russian)

[7] Voronin A.A., Vasilchenko A.A., Khrapov S.S., Agafonnikova E.O. Efficiency analysis for nature restoration projects in ecologo-economic system of Volga HPP and Volga-Akhtuba floodplain, Large systems control, 52, 2014, 133-147. (in Russian)

[8] Voronin A.A., Vasilchenko A.A., Pisareva M.V., Pisarev A.V., Khoperskov A.V., Khrapov S.S., Podschipkova Yu.E. Designing a system for ecologicaleconomical management of the VolgaAkhtuba floodplain on basis of hydrodynamic and geoinformational simulation // Large systems control, 55, 2015, 79-102. (in Russian)

[9] Voronin A.A., Eliseeva M.V., Pisarev A.V., Khoperskov A.V., Khrapov S.S. Simulation models of surface water dynamics using remote sensing data: effect of terrain, Caspian journal: management and high technologies, 3 (19), 2012, 54-62. (in Russian)

[10] Khoperskov A.V., Khrapov S.S., Pisarev A.V., Voronin A.A., Eliseeva M.V., Kobelev I.A. The regimen control task in the ecological-economic system "Volzhskaya hydroelectric power station - the Volga-Akhtuba floodplain". I. Simulation of dynamics of surface water during spring floods, Control Sciences, 5, 2012, 18-25. (in Russian)

[11] Khoperskov A.V., Khrapov S.S., Pisarev A.V. Direct modeling of the surface waters dynamics in the Volga-Akhtuba floodplain, Supercomputer technologies in science, education and industry, 3, 2012, 177-181. (in Russian)

[12] Pisarev A.V., Khrapov S.S., Voronin A.A., Dyakonova T.A., Tsirkova E.A. The role of infiltration and evaporation in the flooding dynamics of the Volga-Akhtuba floodplain, Science Journal of Volgograd State University. Mathematics. Physics, 1 (16), 2012, 3641, DOI:10.15688/jvolsu1.2012.1.5. (in Russian)

[13] Khrapov S., Pisarev A., Kobelev I., Zhumaliev A., Agafonnikova E., Losev A., Khoperskov A. The Numerical Simulation of Shallow Water: Estimation of the Roughness Coefficient on the Flood Stage, Advances in Mechanical Engineering, 5, 2013, Article ID 787016, DOI:10.1155/2013/787016. 